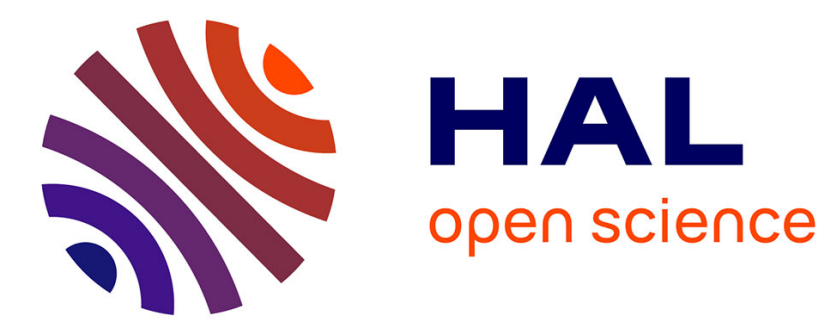

\title{
Thin films sputtered from Ba2NdFeNb4O15 multiferroic targets on BaFe12O19 coated substrates
}

\author{
Romain Bodeux, Dominique Michau, Mario Maglione, Michaël Josse
}

\section{To cite this version:}

Romain Bodeux, Dominique Michau, Mario Maglione, Michaël Josse. Thin films sputtered from Ba2NdFeNb4O15 multiferroic targets on BaFe12O19 coated substrates. Materials Research Bulletin, 2016, 81, pp.49-54. 10.1016/j.materresbull.2016.04.027 . hal-01323323

\section{HAL Id: hal-01323323 \\ https://hal.science/hal-01323323}

Submitted on 30 Jun 2016

HAL is a multi-disciplinary open access archive for the deposit and dissemination of scientific research documents, whether they are published or not. The documents may come from teaching and research institutions in France or abroad, or from public or private research centers.
L'archive ouverte pluridisciplinaire HAL, est destinée au dépôt et à la diffusion de documents scientifiques de niveau recherche, publiés ou non, émanant des établissements d'enseignement et de recherche français ou étrangers, des laboratoires publics ou privés. 


\section{Thin films sputtered from $\mathrm{Ba}_{2} \mathrm{NdFeNb}_{4} \mathrm{O}_{15}$ multiferroic}

\section{targets on $\mathrm{BaFe}_{12} \mathrm{O}_{19}$ coated substrates}

3

4 Romain Bodeux, Dominique Michau*, Mario Maglione and Michaël Josse

5

6

7 ICMCB-CNRS, Université de Bordeaux, 87 avenue du Dr. A. Schweitzer, Pessac F-33608,

8 France

9

10

$11 *$ Author to whom correspondence should be addressed. Electronic mail:

12 d.michau@icmcb-bordeaux.cnrs.fr

13

14

15

16

17

18 


\section{Abstract}

2

$3 \mathrm{Ba}_{2} \mathrm{NdFeNb}_{4} \mathrm{O}_{15}$ tetragonal tungsten bronze (TTB) / $\mathrm{BaFe}_{12} \mathrm{O}_{19}(\mathrm{BaM})$ hexaferrite bilayers

4 have been grown by RF magnetron sputtering on $\mathrm{Pt} / \mathrm{TiO}_{2} / \mathrm{SiO}_{2} / \mathrm{Si}(\mathrm{PtS})$ substrates. The $\mathrm{BaM}$

5 layer is textured along (001) while the TTB layer is multioriented regardless of the PtS or

6 BaM/PtS substrate. Dielectric properties of TTB films are similar to those of bulk, i.e., $\varepsilon \sim$

$7 \quad 150$ and a magnetic hysteresis loop is obtained from TTB/BaM bilayers, thanks to the BaM

8 component. This demonstrates the possibility of transferring to 2 dimensional structures the

9 composite multiferroic system $\mathrm{TTB} / \mathrm{BaM}$ previously identified in 3 dimensional bulk

10 ceramics.

11

12

13 KEYWORDS: A. magnetic materials, A. multilayers, B. sputtering, C. impedance 14 spectroscopy, D. multiferroics

15 


\section{1) Introduction}

2

3 "The world Multiferroic" was coined for materials in which ferroic orders, i.e. ferroelectricity

4 (FE), ferromagnetism (FM), ferroelasticity,... coexist in the same phase. These

5 multifunctional materials have recently attracted great scientific and technologic interests due

6 to their versatile properties which could lead to potential applications in memory devices,

7 actuator and sensors [1]. Multiferroism can be achieved when, in a single-phased material,

8 one cationic sublattice induces a structural distortion and a polarization, while a second

9 sublattice built of paramagnetic ion induces a magnetization [2]. However such materials are

10 relatively unusual and many efforts have been dedicated to "multiferroic composite

11 materials", which associate two ferroic phases [3]. Commercial magnetoplumbite type barium

12 ferrite $\mathrm{BaFe}_{12} \mathrm{O}_{19}(\mathrm{BaM})$ is a good candidate for the design of multiferroic composites because

it is a hard magnet, with a large uniaxial anisotropy which could be useful in micro- or

nanostructured materials. Different devices were recently investigated combining BaM with a

ferroelectric material, i.e. $\mathrm{SrBa}_{2} \mathrm{Ta}_{2} \mathrm{O}_{9} / \mathrm{BaM}$ thin films heterostructures [4], multilayers

consisting of alternating $\mathrm{BaM}$ layers with $\mathrm{Pb}(\mathrm{Zr}, \mathrm{Ti}) \mathrm{O}_{3}(\mathrm{PZT})$ [5] or $(\mathrm{Ba}, \mathrm{Sr}) \mathrm{TiO}_{3}$ (BST)

17 perovskite layers [6-11] and self-assembled BaM clusters embedded in a PZT or BST matrix

[12-14]. It was also shown that $\mathrm{BaTiO}_{3} / \mathrm{BaM}$ ceramics exhibit magnetoelectric coupling at room temperature $[15,16]$.

The main aim of the present paper is to show that tetragonal tungsten bronze niobiates can be

21 alternative compounds for the processing of such composite multiferroics. TTB forms an 22 important family of dielectric materials. Their general formula $(\mathrm{A} 1)_{4}(\mathrm{~A} 2)_{2}(\mathrm{C})_{4}(\mathrm{~B} 1)_{2}(\mathrm{~B} 2)_{8} \mathrm{O}_{30}$ 23 allows many cationic substitution that leads to tunability in their physical properties. Thus 24 TTB could be easily compatible with coexistance of ferroelectricity and ferromagnetism after 25 the introduction of paramagnetic cations. Original bulk multiferroics composites were already 
1 identified in the $\mathrm{Ba}_{2} \mathrm{LnFeNb}_{4} \mathrm{O}_{15}$ (Ln:TTB) family ( $\mathrm{Ln}=\mathrm{Nd}, \quad \mathrm{Sm}$ and $\left.\mathrm{Eu}\right)[17,18]$.

2 Ferroelectric behaviour in this family is driven by the size of the rare earth ions and their

3 accommodation leads to the formation of a small amount of barium ferrite BaM. This

4 magnetic phase is generated in situ during the ceramic processing, which indicates a very high

5 chemical stability of both FE and FM phases in this composite system. Castel and al.

6 investigated the elaboration of Eu:TTB composite samples with an excess of hematite in the

7 nominal composition [19], while Roulland et al. tuned the Europium content in Eu:TTB [20].

8 They have shown that the magnetic response is modulated by the amount barium ferrite,

9 which can be increased with excess of hematite or reduced by diminishing the rare earth content. More recently, Ta substitution for $\mathrm{Nb}$ was identified as another crystal chemical lever to control these multiferroic composites [21]. Attempts to induce the formation of barium ferrite in other TTB structured system proved unsuccessful, revealing how special the $\mathrm{Ba}_{2} \mathrm{LnFeNb}_{4} \mathrm{O}_{15}$ composite multiferroic ceramics are rare [22]. Thus multiferroic composites based on these TTBs, in which ferroelectric properties and magnetization can be tuned, are of interest. In this view, it is important to investigate Ln:TTB thin film deposited on BaM coated substrate. Stability and chemical compatibility of BaM with Ln:TTB is a real advantage for this heterostructure, although it seems particularly complex and requires optimum growth for both TTB and BaM layers. Previous reports on individual BaM and TTB films are encouraging for the development of such systems,. On the one hand, BaM thin films deposited on PtS were widely studied because a Pt underlayer favors the growth along the easy axis of magnetization, required for applications $[23,24]$. On the other hand, relaxor TTB thin films were deposited by RF magnetron sputtering on $\operatorname{Pt}(111)$ and showed dielectric properties very close to those of bulk ceramics $[25,26]$. In the present work, we compare growth orientation, microstructure and dielectric properties of $\mathrm{Ba}_{2} \mathrm{NdFeNb}_{4} \mathrm{O}_{15}$ films deposited on silicon with $\mathrm{Pt}$ or $\mathrm{BaM} / \mathrm{Pt}$ intermediate layers. We find 
1 that the ferromagnetic properties of $\mathrm{BaM}$ and the intrinsic TTB dielectric behaviour are kept

2 in such bi-layers. More interestingly, because of the good chemical and structural

3 compatibility between the two phases, possible magneto-dielectric coupling is anticipated.

\section{2) Experiments}

$\mathrm{Ba}_{2} \mathrm{NdFeNb}_{4} \mathrm{O}_{15}$ tetragonal tungsten bronze (TTB) and $\mathrm{BaFe}_{12} \mathrm{O}_{19}(\mathrm{BaM})$ ceramic targets were prepared through a solid state route. TTB target was sintered at $1300^{\circ} \mathrm{C}$ from stoichiometric mixture of $\mathrm{BaCO}_{3}, \mathrm{Fe}_{2} \mathrm{O}_{3}, \mathrm{Nb}_{2} \mathrm{O}_{5}$ and $\mathrm{Nd}_{2} \mathrm{O}_{3}$ [25] while $\mathrm{BaM}$ was sintered at $1000^{\circ} \mathrm{C}$ from stoichiometric mixture of $\mathrm{BaCO}_{3}$ and $\mathrm{Fe}_{2} \mathrm{O}_{3}$. The purity of the targets was checked by XRD using small control pellets sintered with the targets.

TTB films were grown on $\mathrm{Pt}(111) / \mathrm{TiO}_{2} / \mathrm{SiO}_{2} / \mathrm{Si}(100)(\mathrm{PtS})$ and $\mathrm{BaM} / \mathrm{PtS}$ substrates by $\mathrm{RF}$ magnetron sputtering (Plassys PM450 - $13.56 \mathrm{MHz}$ ) [19]. During all depositions, the atmosphere pressure of 40 mTorr was a mixture of $10 \% \mathrm{O}_{2}$ and $90 \%$ Ar. PtS substrates were purchased from INOSTEK and appropriate masking during the films deposition enabled the use of the Pt underlayer as the bottom electrode. The deposition parameters of BaM films were optimized regarding crystalline quality and following previous reports [23,24]. All BaM films were deposited at $300{ }^{\circ} \mathrm{C}$. Crystallization took place in a tubular furnace during the post deposition annealing step at $850^{\circ} \mathrm{C}$ for $3 \mathrm{H}$ in oxygen atmosphere. TTB films were deposited at $300{ }^{\circ} \mathrm{C}$ and post annealed at $800^{\circ} \mathrm{C}$ for $1 \mathrm{H}$ in oxygen atmosphere. Films thickness was measured using a Veeco Dektak6M stylus profile mechanical profilometer. Various thicknesses of layer were obtained by appropriately tuning the deposition time, the thickness of TTB layers varying between $250 \mathrm{~nm}$ and $1000 \mathrm{~nm}$, that of BaM layers one varying between 0 and $200 \mathrm{~nm}$ (table 1). X-ray diffraction data in the $\theta-2 \theta$ Bragg-Brentano geometry were recorded on a Philips XPert pro diffractometer $\left(\mathrm{Cu} \mathrm{K} \alpha_{1}\right.$ radiation, $\lambda=1.54056$ 
$1 \AA$ A) with $10^{\circ}<2 \theta<80^{\circ}$ and step $=0.02^{\circ}$. Sample's surface morphology was examined by

2 atomic force microscopy (Veeco dimension 3100). Magnetic hysteresis loops were measured

3 on a SQUID magnetometer (MPMS, Quantum Design Inc.) on samples cut to small pieces

4 compatible witht the sample holder. Pt Circular dots were deposited ex-situ at room

5 temperature as a top electrode by dc sputtering through a metal mask at room temperature.

6 The dot geometry defined the capacitors area: $\mathrm{S}=0.1 \mathrm{~mm}^{2}$. Dielectric properties of capacitors

7 were measured in the metal/insulator/metal configuration using a Hewlett-Packard 4194

8 impedance analyser as a function of frequency $(100 \mathrm{~Hz}-1 \mathrm{MHz}$ ) and temperature (on

9 heating) with an ac excitation amplitude of $100 \mathrm{mV}$.

\section{3) Results and discussion}

After standard solid state processing of powders and dense ceramics, X-ray diffraction (XRD) evidenced the successful stabilisation of the tetragonal tungsten bronze structure for the compound $\mathrm{Ba}_{2} \mathrm{NdFeNb}_{4} \mathrm{O}_{15}$ (TTB). The XRD pattern of the TTB ceramic target is shown in Fig.1a. Diffraction pattern matches with the reference data for homologous $\mathrm{Ba}_{2} \mathrm{LaNb}_{5} \mathrm{O}_{15}$ TTB (JCPDS 46-0232). In a previous work [27], X-ray microprobe experiment revealed that traces of $\mathrm{BaFe}_{12} \mathrm{O}_{19}(\mathrm{BaM})$ barium ferrite should be present in the target ceramics, although it was not detected by XRD. In fact, chemical strain and distortions induced by smaller rare earths lead to the evolution of the TTB compositions and the occurrence of secondary phases,

21 i.e. $\mathrm{LnNbO}_{4}$ fergusonite and $\mathrm{BaM}$.

Fig. $1 \mathrm{~b}$ shows the $\mathrm{XRD}$ pattern of a sputtered films deposited at $300^{\circ} \mathrm{C}$ and of a film postannealed at $800^{\circ} \mathrm{C}$ (sample $\mathrm{A}$ in table 1 ). After deposition the films were amorphous and postannealing was required to trigger crystallisation. The annealed films displayed a diffraction pattern compatible with the TTB structure, with several peaks easily identified by comparison 
1 with the ceramic target. The films were polycrystalline and the diffraction peaks exhibited a

2 distribution of relative intensity rather similar to that of ceramics. A notable exception to 3 these intensity ratio is found with (001) peaks, the amplitude of which is significantly larger

4 than in the ceramics. This suggests a partial texturation of the polycrystalline film along [001]

5 . The overall multioriented growth of films is nonetheless in agreement with other post6 annealed compounds of the same family [28]. The mismatch of peak positions with those of 7 ceramic indicates that the films are compressive strained. Strain can be induced by the lattice misfits between TTB and Pt at the interface or produced by the intrinsic stress during the postannealing. The diffraction peaks, which are relatively narrow, suggest a good quality of the films. The full width at half maximum (FWHM) of $\operatorname{TTB}(001)$ reflection is $\Delta 2 \theta=0.19^{\circ}$ which

11 is close to that of $\operatorname{Pt}(111)$ which is $\Delta 2 \theta=0.20^{\circ}$. An average crystallite size of about $50 \mathrm{~nm}$ was obtained by the Scherrer's formula.

The use of $\mathrm{BaFe}_{12} \mathrm{O}_{19}(\mathrm{BaM})$ for high density magnetic recording applications requires thin 14 films with perpendicular c-axis orientation, because of BaM large magnetic anisotropy. Caxis growth of BaM can be obtained by using a Pt underlayer [23,29-33]. However, high temperature deposition is required to produce $\mathrm{BaM}$ films with high quality by RF magnetron sputtering and post annealing was generally undertaken [24]. Our preliminary works are in agreement with these previous reports. XRD pattern are shown in Fig. 2 for the BaM films deposited on PtS(111) with optimized conditions (sample C) in table 1. The BaM films displayed intense (001) peaks, indicating that the films are crystallized and suggesting a (001) texture. From the crystallography view point, the (111) plane of packed Pt atoms is seen as a hexagonal structure with a lattice constant $\mathrm{a}=5.547 \AA$, which is close enough from $(001)$ plane of the hexagonal $\mathrm{BaM}$ structure with $\mathrm{a}=5.892 \AA$. The relatively small mismatch between $\operatorname{Pt}(111)$ and $\mathrm{BaM}(001)$ favors the c-axis orientation of the $\mathrm{BaM}$ layer. The TTB films were deposited on $\mathrm{BaM} / \mathrm{PtS}$ in the same deposition conditions than the ones on PtS, i.e. as- 
1 deposited TTB films were amorphous and crystallization took place during the post 2 deposition annealing step at $800{ }^{\circ} \mathrm{C}$ (sample E). Fig.2 shows XRD pattern for the 3 TTB/BaM/PtS stack (sample E). TTB films are multioriented while BaM remains textured 4 (001), and this results demonstrates the successful deposition of TTB on the BaM phase to 5 form a bilayer. The peaks of the BaM layer are well defined indicating that the integrity of the $6 \mathrm{BaM}$ phase was preserved through the second heat treatment. More interesting, the 7 introduction of a BaM buffer layer restores the random orientation of the grains in the TTB 8 film. Generally, when synthesizing bi- or multilayers, the structure is significantly affected by 9 the under-layer structure. The under-layer can lead to strains of the top layer crystal lattice and partial texturing. However, the large mismatch of both $\mathrm{Pt}$ and $\mathrm{BaM}$ with the tetragonal structure of TTB layer $(\mathrm{a} \sim 12.48 \AA$ in the ceramic) should induce disorder and dislocations at the interface. The interaction between $\mathrm{BaM} / \mathrm{Pt}$ and TTB confines at the interface. Thus, the structure within TTB layer remains unchanged and random orientations of grains take place. Furthermore growth procedure can play a significant role on the TTB structure. In fact, we observed similar results on ceramic composites, which are obtained from solid state route consisting in a mixture followed by sintering at highest temperature $\sim 1200^{\circ} \mathrm{C}$, i.e. both $\mathrm{TTB}$ and $\mathrm{BaM}$ phases were maintained. This shows that these two phases coexist without any intermixing in these thermodynamical conditions.

Fig. 3a and Fig 3b show the typical morphology of the surface for TTB films deposited on PtS and $\mathrm{BaM} / \mathrm{PtS}$ substrates (sample A and sample E, respectively). The grains are distinctly visible, assuming that the films are well crystallized, as confirmed by XRD. The grains are densely and regularly packed without cracks or voids and the surfaces are relatively uniform and smooth. The film shows a granular surface with a regular and fine grain size about $50 \mathrm{~nm}$ which is comparable to the crystallite size obtained from XRD data. The granular surface of films is typical of post-annealed films formed from amorphous film precursors. It was also 
1 observed in others materials [34] and is relatively independent of the buffer layer [35,36]. The

2 root-mean-square (rms) roughness surface roughness is about $4.4 \mathrm{~nm}$ and $7.6 \mathrm{~nm}$ for PtS and

$3 \mathrm{BaM} / \mathrm{PtS}$ substrates. The higher value for $\mathrm{BaM} / \mathrm{PtS}$ has to be associated with the roughness of

$4 \mathrm{BaM}$ (about $13.3 \mathrm{~nm}$ ) which leads to dark areas on the picture obtained from TTB/BaM/PtS

5 stacks. However, the peak-valley distance $(50 \mathrm{~nm})$ is clearly lower than the thickness of all

6 TTB films $(>250 \mathrm{~nm})$. Therefore, the TTB films are suitable for dielectric measurements in

7 metal/insulator/metal configuration.

Ferromagnetic response of $\mathrm{Ba}_{2} \mathrm{NdFeNb}_{4} \mathrm{O}_{15}$ ceramics is related to the presence of

small amount of barium ferrite and this spontaneous magnetization reaches $\mathrm{M}_{\mathrm{S}} \sim 1 \mathrm{emu} / \mathrm{g}$ at

$10 \mathrm{kOe}$ [27]. The smaller quantity of matter in the films (three orders of magnitude with respect to ceramics), would yield traces of in situ formed BaM, which should not be sufficient to overcome the diamagnetic response of $\mathrm{PtS}$ substrate, i.e. $\mathrm{M}_{\mathrm{dia}} \sim 2$ memu per gram of $\mathrm{PtS}$ substrate at $10 \mathrm{kOe}$ (not shown). However, the magnetic properties of TTB composites can be controlled by inducing the formation of an excess of barium ferrite [19]. In this view, the elaboration of TTB/BaM/PtS stacks should allow to investigate a layered architecture, which could be used as a model system of the corresponding ceramic system. Magnetic hysteresis loops of such a stack (sample E) at $300 \mathrm{~K}$ are shown in Fig. 4. The stack exhibits large remanence, as expected for a single BaM layer. The loop is attributed to the prevailing easyaxis of magnetization along the $\operatorname{BaM}(001)$ orientation [23]. Spontaneous magnetization reaches $\sim 7.10^{-3}$ emu per gram of PtS substrate while the coercive field is about $1 \mathrm{kOe}$, which 21 is consistent with the values reported for BaM films [37].

22 The capacitance $\mathrm{C}$ was extracted from impedance measurements $Z^{*} Z^{\prime}$-jZ''. The dielectric losses were related to the complex impedance through the relation $\tan \delta=Z^{\prime} / Z^{\prime}$ '. In figure 5

24 is shown the frequency dependence of capacitance and the dielectric losses for the $25 \mathrm{TTB} / \mathrm{BaM} / \mathrm{PtS}$ stacks with various thicknesses of BaM layer, 0, 100 et $200 \mathrm{~nm}$ (sample A, E 
1 and $\mathrm{B}$, respectively). Below $10 \mathrm{kHz}$, capacitance exhibits a constant value about $5 \mathrm{nF} / \mathrm{mm}^{2}$ for

2 the stack with a BaM layer thickness of $100 \mathrm{~nm}$, similar to the one observed in a TTB single

3 layer. The capacitance slightly decreases about $3.5 \mathrm{nF} / \mathrm{mm}^{2}$ when the BaM layer thickness

4 increases, as discussed below. Thus, the dielectric properties of TTB films are maintained

5 when deposited on the BaM buffer layer. These results are consistent with the XRD and AFM

6 measurements which show that the TTB layer is not affected by the BaM layer. To values

7 greated than $10 \mathrm{kHz}$, a decrease of capacitance is observed for the TTB/BaM/PtS stack. The

8 relaxation in capacitance is accompanied by a broad peak in $\tan \delta$ at $\mathrm{f}=300 \mathrm{kHz}$, which doe

9 not appear in the TTB/PtS stack. For the TTB/PtS stack, the limited increase of dielectric

10 losses at $1 \mathrm{MHz}$ is an artefact arising from the stray inductance of the contacts. The

11 appearance of a dielectric anomaly on TTB/BaM/PtS stacks suggests that it is related to the

12 insertion of the $\mathrm{BaM}$ layer. $\mathrm{BaM}$ is extensively used in the microwaves devices because of its

13 high resistivity which allows minimizing the losses. This dielectric response of the BaM layer

14 may act as an additional impedance source on the impedance measurements connected in

15 series to the TTB film [36]. From these results, the dielectric response can be modelled and

16 analysed using two RC parallel electrical elements, one corresponding to TTB film and the

others to an interface capacitance. The contribution of each of these elements to the dielectric

response is then visible over characteristic frequency ranges, i.e. $\omega=(\mathrm{RC})^{-1}$. Thus, the

19 dielectric response of the TTB layer dominates at low frequency while that of the BaM layer appears at high frequency.

To further analyse the size effect in stacks, the dielectric properties of four TTB/BaM

stacks were studied for which the TTB layer were deposited at various thicknesses: 250, 500, 750 and $1000 \mathrm{~nm}$ (sample D, E, F and G, respectively). The frequency dependence of 24 capacitance and $\tan \delta$ are shown in Fig. 6a and 6b, respectively. The capacitance slightly 
1 increases from $2.1 \mathrm{nF} / \mathrm{mm}^{2}$ to $4.8 \mathrm{nF} / \mathrm{mm}^{2}$ when the thickness of the TTB layer decreases for

2 the high frequency range $\mathrm{f}<100 \mathrm{kHz}$,

3 A large increase of capacitance is observed when the frequency decreases below $100 \mathrm{kHz}$,

4 especially for the $250 \mathrm{~nm}$ TTB layer. It is accompanied by a large relaxation in $\tan \delta$. The

5 largest capacitance is associated with the thinner TTB layer. In this analysis, the stack capacitance $\mathrm{C}_{\text {stack }}$ can be written as

7

$8 \quad \frac{1}{C_{\text {stack }}}=\frac{1}{C_{T T B}}+\frac{1}{C_{B a M}}=\frac{t_{T T B}}{\varepsilon_{T T B} S}+\frac{t_{B a M}}{\varepsilon_{B a M} S}$

where $\mathrm{C}_{\mathrm{TTB}}, \mathrm{C}_{\mathrm{BaM}}, \varepsilon_{\mathrm{TTB}}, \varepsilon_{\mathrm{BaM}}, \mathrm{t}_{\mathrm{TTB}}$ and $\mathrm{t}_{\mathrm{BaM}}$ denotes the capacitances, the permittivity and the thickness of the TTB and BaM layers, respectively. By plotting $1 / \mathrm{C}_{\text {stack }}$ vs $\mathrm{t}_{\mathrm{TTB}}$ and $\mathrm{t}_{\mathrm{BaM}}$ curves at low frequency, $\mathrm{f}=100 \mathrm{~Hz}$, and high frequency, $\mathrm{f}=1 \mathrm{MHz}$, from the inset figures 5 and 6 , we determine from their slopes the experimental values of $\varepsilon_{\mathrm{TTB}} \sim 150$ and $\varepsilon_{\mathrm{BaM}} \sim 40$ which are consistent with ones reported in the literature $[26,38]$ function of the temperature at various frequencies $10 \mathrm{kHz}, 100 \mathrm{kHz}$ and $1 \mathrm{MHz}$ in Fig. 7. Capacitance exhibits a steplike feature from a low-temperature plateau value of $1.6 \mathrm{nF} / \mathrm{mm}^{2}$ towards $2.5 \mathrm{nF} / \mathrm{mm}^{2}$ at high temperatures. The step shifts to higher temperatures with increasing frequency. This typical signature is commonly reported as a Maxwell Wagner relaxation [39]. This relaxation is caused by the contribution of two different electrical elements evidenced in Figure 5 and 6, such as the TTB layer capacitance visible at high temperature and low frequency and the BaM layer capacitance observed at low temperature and high frequency. In addition, the step in $\mathrm{C}(\mathrm{T})$ is transferred into a peak in $\tan \delta(\mathrm{T})$. The characteristic frequency $\left(f_{r}\right)$ of this relaxation is governed by the resistance and capacitance of both TTB and BaM layers according to the relation [39] 
4 From Fig. 6 and Fig. 7, it appears that on the one hand $\mathrm{R}_{\mathrm{TTB}}$ and $\mathrm{R}_{\mathrm{BaM}}$, and on the other hand $5 \mathrm{C}_{\mathrm{TtB}}$, and $\mathrm{C}_{\mathrm{BaM}}$ are the same order of magnitude and therefore each term contributes 6 significantly to the relaxation. The peak shifts to the highest temperatures as the frequency is 7 increased. The relaxation frequency was fitted with an Arrhenius law with a characteristic 8 activation energy $\mathrm{E}_{\mathrm{a}} \sim 0.34 \mathrm{eV}$. In hexaferrites, the conductivity arises mainly with 9 temperature from electron hopping between $\mathrm{Fe}^{3+}$ and $\mathrm{Fe}^{2+}$ cations. caused by the presence of oxygen vacancies. The activation energy of this mechanism is about $0.3 \mathrm{eV}$ and could explain 11 the relaxation observed in our TTB/BaM stacks [40]. For a TTB single layer, a lowtemperature anomaly was also observed and was likely related to a relaxor behaviour [24]. A similar value of activation energy of $0.3 \mathrm{eV}$ was reported although the anomaly is shifted to lower 14 temperatures with respect to the Maxwell-Wagner relaxation observed in the stacks. Both mechanisms are rather different, but one should keep in mind that $\mathrm{Fe}^{3+}$ cations are also present in TTB compound.

16 Moreover in TTB single crystals, $\mathrm{Fe}^{0,2+, 3+}$ ions were detected from XPS spectra and were associated with reduced niobium ions $\left(\mathrm{Nb}^{5+, 4+, 3+}\right)$. Significant dielectric losses were clearly seen in these crystals and may be related to electron hopping within the octahedral framework, as it is statistically occupied by iron and nobium ions. [18]. Further investigation is needed to assess the mechanisms involved both in TTB single layers and in TTB/BaM stacks. Anyhow, the results presented here demonstrate a good potential for the coexistence of ferroelectricity and ferromagnetism in TTB/BaM bilayer thin films. We plan to improve their quality by different synthesis route in order to look for a magnetocapacitance effect.

\section{4) Conclusion}


1 Tetragonal tungsten bronze and barium ferrite films from $\mathrm{Ba}_{2} \mathrm{NdFeNb}_{4} \mathrm{O}_{15}$ (TTB) and

$2 \quad \mathrm{BaFe}_{12} \mathrm{O}_{19}(\mathrm{BaM})$ homemade ceramic targets were obtained by $\mathrm{RF}$ magnetron sputtering on $\mathrm{Pt}$

3 and postannealed. It was found that growth orientation, microstructure and dielectric

4 properties of the TTB layer were retained regardless of the underlayer (Pt bottom electrode or

$5 \mathrm{BaM})$. A dielectric relaxation appears on $\mathrm{Pt} / \mathrm{TTB} / \mathrm{BaM} / \mathrm{PtS}$ stacks and suggests that the

6 insertion of the $\mathrm{BaM}$ layer provides an additional impedance source. The capacitance of the

7 TTB layer is visible at high temperature and low frequency whereas that of BaM layer is 8 observed at low temperature and high frequency. The relaxation frequency follows an

9 Arrhenius relationship with a characteristic activation energy $\mathrm{E}_{\mathrm{a}} \sim 0.34 \mathrm{eV}$, and is likely 10 related to a Maxwell-Wagner effect. Magnetic hysteresis loops were obtained from the stacks, 11 and are consistent with the magnetic properties of the BaM layer. The loop is attributed to the 12 prevailing easy-axis of magnetization along the $\mathrm{BaM}(001)$ orientation. This allows for further 13 development of $\mathrm{TTB} / \mathrm{BaM} / \mathrm{PtS}$ bilayers and multilayers as multiferroic and possibly 14 magnetoelectric composites.

16 Acknowledgments

17

18 This project was supported by the French Agency for Research under contract ANR

CROCRODIEL(Grant ANR-09-JCJC-0079). 


\section{Reference}

[1] L.W. Martin, Y. -H. Chu and R. Ramesh, Mater. Sci. and Eng. R 68 (2010) 89.

[2] A. M. dos Santos, S. Parashar, A. R. Raju, Y. S. Zhao, A. K. Cheetham and C. N. Rao, Solid State Commun. 122 (2002) 49.

[3] C-W Nan, M.I. Bichurin, Shuxiang Dong, D. Viehland and Srinivasan, J. Appl. Phys. 103 (2008) 031101.

[4] D. Chen, I. Harward, K. Linderman, E. Economou, Y. Nie, and Z. Celinski, J. Appl. Phys. $115(2014)$ 17D713

[5] G. Srinivasan, I. V. Zavislyak and A. S. Tatarenko, Appl. Phys. Lett. 89 (2006) 152508.

[6] N.A. Frey, R. Heindl, S. Srinath, H. Srikanth, N.J. and Dudney, Mater. Res. Bull. 40 (2005) 1286.

[7] S. Srinath, N. A. Frey, R. Heindl, H. Srikanth, K. R. Coffey and N. J. Dudney, J. Appl. Phys. 97 (2005) 10J115

[8] R. Heindl, H. Srikanth, S. Witanachchi, P. Mukherjee, A. Heim, G. Matthews, S. Balachandran, S. Natarajan and T. Weller, Appl. Phys. Lett. 90 (2007) 252507.

[9] R. Heindl, H. Srikanth, S. Witanachchi, P. Mukherjee, T. Weller, A. S. Tatarenko and G. Srinivasan, Appl. Phys. Lett. 101 (2007) 09M503

[10] Y.-Y. Song, J. Das, P. Krivosik, N. Mo and C.E. Patton, Appl. Phys. Lett. 94 (2009) 182505.

[11] J. Das, Y.-Y. Song and M. Wu, J. Appl. Phys. 108 (2010) 043911.

[12] R. Hajndl, J. Sanders, and H. Srikanth, J. Appl. Phys. 93 (2003) 7999.

[13] D. V. Karpinsky, R. C. Pullar, Y. K. Fetisov, K. E. Kamentsev and A. L. Kholkin J. Appl. Phys. 108 (2010) 042012. 
1 [14] J. D. S. Guerra, Madhuparna Pal, R. J. Portugal, L. F. Cótica, I. A. Santos, R. Guo, and

$2 \quad$ A. S. Bhalla, J. Appl. Phys. 114 (2013) 224113

3 [15] A. Srinivas, R. Gopalan and V. Chandrasekharan, Solid State Commun. 149 (2009) 367

4 [16] H. Trivedi,V.V. Shvartsman, D.C. Lupascu, M.S. A. Medeiros, R.C. Pullar, A.L.

$5 \quad$ Kholkin, P. Zelenovskiy, A. Sosnovskikhd and V. Y. Shurd, Nanoscale 7 (2015) 4489

6 [17] E. Castel, P. Veber, M. Albino, M. Velazquez, S. Pechev, D. Denux,J.P. Chaminade, M.

7 Maglione ,M. Josse, J. Cryst. Growth 340 (2012) 156

8 [18] M. Albino, P. Veber, S. Pechev, C. Labrugère, M. Velazquez, M. Maglione and M.

9 Josse, Cryst. Growth Des., 14 (2014) 500

10 [19] E. Castel, M. Josse , F. Roulland, D. Michau, L. Raison and M. Maglione, J. Magn 11 Magn. Mater. 321 (2009) 1773.

12 [20] F. Roulland, M. Josse, E. Castel and M. Maglione, Solid State Sci. 11 (2009) 1709.

13 [21] E. Castel, M. Maglione, M. Josse, submitted to Solid State Sci.

14 [22] M. Josse, P. Heijboer, M. Albino, F. Molinari, F. Porcher, R. Decourt, D. Michau, S.

Pechev, P. Veber, M. Velazquez, M. Maglione, Cryst. Growth Des., 2014, 14(11), 5428-5435

[23] X. Sui, B.-K. Cheong, D. E. Laughlin and M. H. Kryder, J. Magn. Soc. Jpn 18-S1 (1994) 17319.

[24] A. Morisako, T. Naka, K. Ito, A. Takizawa, M. Matsumoto and Y.-K. Hong, J. Magn Magn. Mater. 242 (2002) 304.

[25] Michau et A. Simon et M. Maglione, J. Phys. D 42(7), (2009) 075407

21 [26] R. Bodeux, D. Michau, M. Josse and M. Maglione, Solid State Sci., 38 (2014) 112.

22 [27] M. Josse, O. Bidault, F. Roulland, E. Castel, A. Simon, D. Michau, R. Von der Mühll, O.

Nguyen and M. Maglione Solid State Sci. 11 (2009) 1118.

[28] S.-K. Park, M.-S. Baek, S.-C. Bae, S.-Y. Kwon, J.-H. Kim and Ki-W. Kim, Solid State

Commun. 111 (1999) 125 
1 [29] X. Sui, M. Scherge, M.H. Kryder, J.E. Snyder, V.G. Harris and N.C. Koon, J. Magn

2 Magn. Mater. 155 (1996) 132.

3 [30] Z. Zhuang, M. Rao, D. E. Laughlin and M.H. Kryder, J. Appl. Phys. 85 (1999) 6142.

4 [31] Z. Zhuang, M.Rao, R. M. White, David E. Laughlin and Mark H. Kryder, J. Appl. Phys. $5 \quad 87(2000) 6370$.

6 [32] N.N. Shams, X. Liu, M. Matsumoto and A. Morisako, J. Magn Magn. Mater. 290 7 (2005) 138.

8 [33] Q. F. Li, X. D. Su, H. Li, L. Zhang, Z. H. Liu and H. J. Zhong, J. Appl. Phys. 106 (2009) 9123914.

10 [34] R. Singh, T.C. Goel and S. Chandra, Mater. Res. Bull. 43 (2008) 384.

11 [35] W. Leng, C. R. Yang, J. H. Zhang, H. W. Chen, H. Ji, C. L. Fu and J. X. Liao, J. Appl. 12 Phys. 99 (2006) 114904.

13 [36] W. Leng, C. Yang, H. Ji, J. Zhang, J. Tang, H. Chen and L. Gao, J. Phys. D 40 (2007) 141206.

15 [37] M. Matsuoka, M. Naoe and Y. Hoshi, J. Appl. Phys. 57 (1985) 4040.

16 [38] R.M. Almeida , W. Paraguassu, D.S. Pires, R.R. Corrêa and C.W. de Araujo Paschoal, 17 Ceram. Int. 35 (2009) 2443.

18 [39] R. Bodeux, M. Gervais, J. Wolfman, C. Autret-Lambert, G. Liu and F. Gervais, Thin 19 Solid Films, 520 (2012) 2632.

20 [40] M. Manikandan and C. Venkatesswaran, J. Magn Magn. Mater. 358 (2014) 82. 
1 Table 1 Thickness of TTB and BaM layers for TTB/BaM/PtS stacks

2

\begin{tabular}{|c|c|c|c|c|c|c|c|}
\hline Parameter & A & B & C & D & E & F & G \\
\hline TTB thickness (nm) & 500 & 500 & 0 & 250 & 500 & 750 & 1000 \\
\hline BaM thickness (nm) & 0 & 200 & 100 & 100 & 100 & 100 & 100 \\
\hline
\end{tabular}

3 
1 Fig1. XRD patterns for a) the TTB ceramic target and b) as deposited TTB/PtS film and

2 annealed TTB/PtS film (sample A)

3

4 Fig.2 XRD patterns for BaM/PtS film (sample C) and TTB/BaM/PtS (sample E) 5

6 Fig. 3 (Color online) Morphology image (AFM) of TTB films deposited on a) PtS (sample A)

7 and b) BaM/PtS (sample E)

8

9 Fig. 4 Magnetization per gram of PtS substrate for the TTB/BaM/PtS stack. Thickness of the 10 BaM layer is $100 \mathrm{~nm}$ (sample E).

11

12 Fig. 5 Frequency dependence of a) capacitance and (b) the dielectric losses for the $\mathrm{Pt} / \mathrm{TTB} / \mathrm{BaM} / \mathrm{PtS}$ with BaM thickness of $0 \mathrm{~nm}$ (sample A), $100 \mathrm{~nm}$ (sample E) and $200 \mathrm{~nm}$

14 (sample B)

15

16 Fig. 6 Frequency dependence of (a) the capacitance and (b) the dielectric losses for the

$17 \mathrm{Pt} / \mathrm{TTB} / \mathrm{BaM} / \mathrm{PtS}$ capacitors with various TTB thicknesses $250 \mathrm{~nm}$ (sample D), $500 \mathrm{~nm}$

18 (sample E), $750 \mathrm{~nm}$ (sample F) and $1000 \mathrm{~nm}$ (sample G)

19

20 Fig. 7 Temperature dependence of a) the capacitance and b) dielectric loss for the

$21 \mathrm{Pt} / \mathrm{TTB} / \mathrm{BaM} / \mathrm{PtS}$ (sample G) for various frequency $10 \mathrm{kHz}, 100 \mathrm{kHz}$ and $1 \mathrm{MHz}$ 